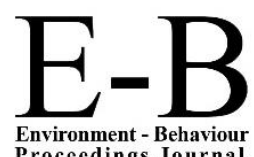

Environment - Behaviour
Procecdings Journal
AIVCE-BS-1, 2020ShahAlam

https://www.amerabra.org; https://fspu.uitm.edu.my/cebs; https://www.emasemasresources.com/ AMEABRA International Virtual Conference on Environment-Bahaviour Studies, ${ }^{\text {st }}$ Series cE-Bs, FSPU, Universiti Teknologi MARA, Shah Alam, 24-25 Jun 2020

\section{e-IPH}

- International Publishing House Ltd United Kingdom

\title{
Factors Contributing to Depressive Disorder among Patients with Retroviral Disease
}

\author{
Nor Hidayah Jaris ${ }^{1}$, Suresh Kumar Chidambaram², Mohd Razali Salleh¹, Salmi Razali1,3 \\ 1 Department of Psychiatry, Faculty of Medicine, Universiti Teknologi MARA, Malaysia \\ 2 Department of Medicine, ${ }^{3}$ Institute of Pathology, Laboratory and Forensic Medicine (I-PPerForM) \\ Universiti Teknologi MARA, 47000 Sungai Buloh, Selangor, Malaysia
}

norhidayahjaris@gmail.com, chikku.suresh@gmail.com, smrazali59@gmail.com,drsalmi@gmail.com

Tel.: +603-61265000

\begin{abstract}
Major depressive disorder (MDD) increases further morbidity and mortality of patients with retroviral disease (RVD) or human immunodeficiency virus (HIV) infection. This study aimed to determine the prevalence of MDD and its contributing factors among them. Depressive symptoms were screened using the Hospital Anxiety Depression Scale (HADS), and MDD was diagnosed with the Mini International Neuropsychiatric Interview (MINI). Of the total 210 RVD patients, 27(12.9\%) had MDD. The contributing factors for MDD include amphetamine-type stimulants use, social support system, and CD4 count. Interventions for RVD patients should include counselling for those abusing drugs, increasing support system and adherence to treatment.
\end{abstract}

Keywords: Retroviral Disease, Human Immunodeficiency Virus, Depression, Support system

eISSN: 2398-4287@ 2020. The Authors. Published for AMER ABRA cE-Bs by e-International Publishing House, Ltd., UK. This is an open access article under the CC BYNC-ND license (http://creativecommons.org/licenses/by-nc-nd/4.0). Peer-review under responsibility of AMER (Association of Malaysian Environment-Behaviour Researchers), ABRA (Association of Behavioural Researchers on Asians) and cE-Bs (Centre for Environment-Behaviour Studies), Faculty of Architecture, Planning \& Surveying, Universiti Teknologi MARA, Malaysia.

DOI: https://doi.org/10.21834/ebpj.v5i14.2336

\subsection{Introduction}

Major depressive disorder (MDD) is a disease of a mind manifested with symptoms of feeling depressed, lack of appetite, weight reduction, sleep difficulties, feeling hopeless, useless, excessive guilt feelings and having negative thoughts as outlined by the Diagnostic and Statistical Manual of Mental Disorders Fifth Edition (DSM-5). MDD among patients with the retroviral disease (RVD) or human immunodeficiency virus (HIV) infection is prevalent. To date, $39 \%$ of them have been identified to have depression (Tran et al., 2019). MDD is a debilitating mental illness that may increase further morbidity and mortality of RVD patients (Todd et al., 2017). RVD patients with MDD have poor adherence to Highly Active Antiretroviral Therapy (HAART) (Tull, Berghoff, Bardeen, Schoenleber, \& Konkle-Parker, 2018) increasing their susceptibility for symptoms of Acquired immunodeficiency syndrome (AIDS) and other complications. Moreover, MDD also predispose RVD patients to devastating psychological complications such as psychosis, early dementia and suicide (Tyree, Vaida, Zisook, Mathews, \& Grelotti, 2019). Given significant negative consequences of depression among RVD patients, it is crucial that this mental illness to be detected and treated early so that RVD patients are able to have the optimum quality of life while experiencing various challenges having this stigmatising illness.

eISSN: 2398-4287@ 2020. The Authors. Published for AMER ABRA cE-Bs by e-International Publishing House, Ltd., UK. This is an open access article under the CC BYNC-ND license (http://creativecommons.org/licenses/by-nc-nd/4.0/). Peer-review under responsibility of AMER (Association of Malaysian Environment-Behaviour Researchers), ABRA (Association of Behavioural Researchers on Asians) and cE-Bs (Centre for Environment-Behaviour Studies), Faculty of Architecture, Planning \& Surveying, Universiti Teknologi MARA, Malaysia. DOI: https://doi.org/10.21834/ebpj.v5i14.2336 


\subsection{Literature review}

Feeling depressed comes in a spectrum from normal sadness to feeling low because of a stressful event, and to severe depression which occurs as part of the manifestation of mental illness. Mental health professionals only considered those who have feelings of depression as a 'case' of MDD when patients fulfilled the criteria of depression in DSM-5. RVD or HIV infections attack the immune system and weakens the mechanisms of defence against diseases and other forms of cancer in people. Infected individuals slowly become immunodeficient as the virus kills and impairs the role of the immune cells. Usually, immune activity is calculated by the count of cells CD4 (Word Health Organization (WHO), 2019). Co-morbidity of MDD or depression among RVD patients is prevalent. Previous researchers have suggested several factors that may contribute to depression among RVD patients. In terms of sociodemographic factors, it has been shown that younger RVD patients have a higher tendency for MDD (Deshmukh, Borkar, \& Deshmukh, 2017). Female RVD patients may have a higher risk to develop depression in comparison to men (Ngum, Fon, Ngu, Verla, \& Luma, 2017). Other crucial contributing factors for depression were low educational level, unemployment and marital status of being a widow or widower and not living with a spouse (Zeng et al., 2019).

Clinically, an important parameter that indicates the strength of the immune system, i.e. CD4 count is a crucial predictor for depression in RVD patients. Scientists indicated that the level of CD4 count of less than 200 cells/ul might lead to depression among RVD patients (Tesfaye \& Bune, 2014). Moreover, the number of HIV viral particles or viral load has also been documented as one of the essential predictors for depression (Radzniwan et al., 2016). Another factor which is vital to increase their risk for depression is concomitant drug misuse. A cohort study conducted in AIDS Centre in the United States found that the use of amphetamine within three months by the RVD patients led to significant depressive symptoms while the use of cannabis alone increased risk of depression (Mimiaga et al., 2013).

Acting in concert with sociodemographic and clinical factors in predisposing RVD patients to depression is the social support system. Patients with RVD experience challenges in career and relationship that may increase the vulnerability to develop depression and affecting their daily activities (Tuan Abdullah et al., 2019). Thus, having good support was found to be an essential coping mechanism for adjustment and act as a buffer towards stress in mental and physical health (Hostinar \& Gunnar, 2015). Positive social support lowered the risk of getting depression and in contrast, less support associated with a higher score of depressive symptoms (Fawzi et al., 2012; Seffren et al., 2018).

While substantial studies have been carried out to investigate contributing factors for depression among RVD patients, there are still gaps of knowledge that need to be fulfilled to inform effective intervention of RVD. Given the feelings of sadness or depression is very subjective, accurate diagnosis, i.e. Major depressive disorder or MDD is crucial so that correct treatment can be offered. Many previous researchers have evaluated depression among RVD patients by screening for the illness only, but yet to diagnose this mental illness properly. Hence, the findings of those studies only informed the results of 'caseness', not the 'case' of depression (Østergaard et al., 2010). Furthermore, locally, there is sparse of data and research investigating illicit substance use and social support system among RVD patients. Previous studies in Malaysia found that female gender, financial support and alcohol consumption were the factors that contribute to common psychological disorders in patients with HIV (Yee et al., 2009). Shane and Koh's research postulated an association between CD4 counts and Hepatitis B co-infection with depression (Shane et al., 2010). A high perceived social support was identified by Terence et al. to lower the risk of depressive disorder among this vulnerable group (Terence et al., 2017). Thus, this study aimed to determine the prevalence of the diagnosis of Major depressive disorder (MDD) among RVD patients and investigate its contributing factors including the sociodemographic factors, clinical factors, adherence to treatment as well as the level of support by family, friends and significant others given to RVD patients.

\subsection{Methodology}

\subsection{Study design, setting and data collection}

This was a cross-sectional study to determine the prevalence of the Major depressive disorder (MDD) among RVD patients receiving Highly Active Antiretroviral Therapy (HAART) and its associated factors. It was carried out in the Infectious Disease Clinic, Hospital Sungai Buloh is one of the public hospitals in Selangor, which provides specialised treatment for infectious disease in Malaysia. It is tertiary and a reference for infectious disease cases from the north region of Selangor. There were about 1000 patients receiving HAART in a month attending this infectious disease clinic.

\subsection{Data collection and assessment tools}

Participants were selected using systematic random sampling. The inclusion criteria include RVD patients aged 18 years old and above, attending an outpatient clinic and receiving HAART, was able to communicate in English or Bahasa Malaysia. Those who had been diagnosed with severe mental illness and had underlying malignancy were excluded from the study. Only RVD patients who gave informed consent voluntarily without coercion were enrolled in the study.

The feelings of depression were screened with the Hospital Anxiety Depression Scale (HADS)(Yahya \& Othman, 2015). The participants who scored eight and above for HADS was 'caseness' of depression and considered as 'probable depression'. This group of participants were interviewed further using the Mini International Neuropsychiatric Interview (MINI) to confirm the 'case' of MDD. The MINI has been used worldwide and validated locally as a structured diagnostic interview instrument. It follows the criteria of the Diagnostic and Statistical Manual of Mental Disorders Fifth Edition (DSM-5)(Mukhtar et al., 2012). Sociodemographic characteristics (including age, gender, ethnicity, level of education, employment status, occupation, total household income, marital status and living 
companion) and clinical factors (including viral load, CD4 count, adherence to medication, treatment regime, side effects of medications, co-morbid substance and duration of illness) were assessed directly from face-to-face interviews with the RVD patients or retrieval of medical records from the hospital electronic record system. Furthermore, the visual analogue scale (VAS) and the Multidimensional Scale of Perceived Social Support (MSPSS) were used to measure adherence to treatment and level of social support from family, friends and significant others) respectively.

\subsection{Statistical Analysis}

Data were analysed using the Statistical Package for the Social Sciences (SPSS) version 23. The factors associated with MDD among RVD patients were analysed with simple logistic regression (SLogR) followed by multiple logistic regression (MLogR) as the data consisted of categorical variables. The sociodemographic factors, clinical factors, adherence to treatment and level of supports from family, friends and significant others were the independent variables entered into the SLogR. Variables with a p-value of less than 0.05 from the SLogR were then included in the MLogR analysis. A p-value of less than 0.05 was considered statistically significant in the MLogR. Model fitness was checked using Hosmer-Lemeshow goodness of fit test. Confounders were adjusted; interactions, multicollinearity and assumptions were also checked. The p-value of less than 0.05 with a confidence interval of $95 \%$ was taken as statistically significant.

\subsection{Ethics}

Ethical approval was obtained from the Medical and Research Ethics Committee of National Clinical Research Center (CRC) Ministry of Health, Medical and Research Ethics Committee (Protocol no NMRR-18-3891-44221), Faculty of Medicine Universiti Teknologi MARA Research Committee, Medical and Research Ethics Committee, Universiti Teknologi MARA, 600-IRMI 5/1/6, REC/47/19 Medical and Research Ethics Committee of the Clinical Research Center (CRC) of the respective hospital prior to commencing the study.

\subsection{Findings}

\subsection{Background of participants}

Of the total 210 participants, the mean age of the participants was $29.72 \pm 9.98$ years and more than three-quarter of the participants were male $(186 ; 88.6 \%)$. More than a half of the participants $(116 ; 55.2 \%)$ were Malay, and others were Chinese $(71 ; 33.8 \%)$, Indian $(21 ; 10 \%)$ and others $(2 ; 1 \%)$. Most of the participants received tertiary education $(113 ; 53.8 \%)$ and completed secondary school $(86$; $41 \%)$. Less than $10 \%$ went to primary school only $(11 ; 5.2 \%)$. Among the participants, 134 were employed, and $16(7.6 \%)$ were unemployed. More than half of participants (134; 63.8\%) were in Bottom 40 group (B40) with total household income less than RM 3860, less than one-third (45; $21.4 \%$ ) were in the Middle 40 group (M40) with household income between RM 3860 and RM 8319 and others $(31 ; 14.8 \%)$ were in the Top 20 group (T20) with the income of more than RM 8319. They were mostly single $(134 ; 63.8 \%)$ and others had a spouse $(76 ; 36.8 \%)$ (Table 1$)$.

\subsection{Prevalence of Major depressive disorder}

There were $47(22 \%)$ probable depression, and among these 27 participants were established to have MDD. Figure 1 shows the different level of severity with $31(14.8 \%)$ of RVD patients had mild depression, $14(6.7 \%)$ had moderate, and 2(1\%) had a severe level of depression.

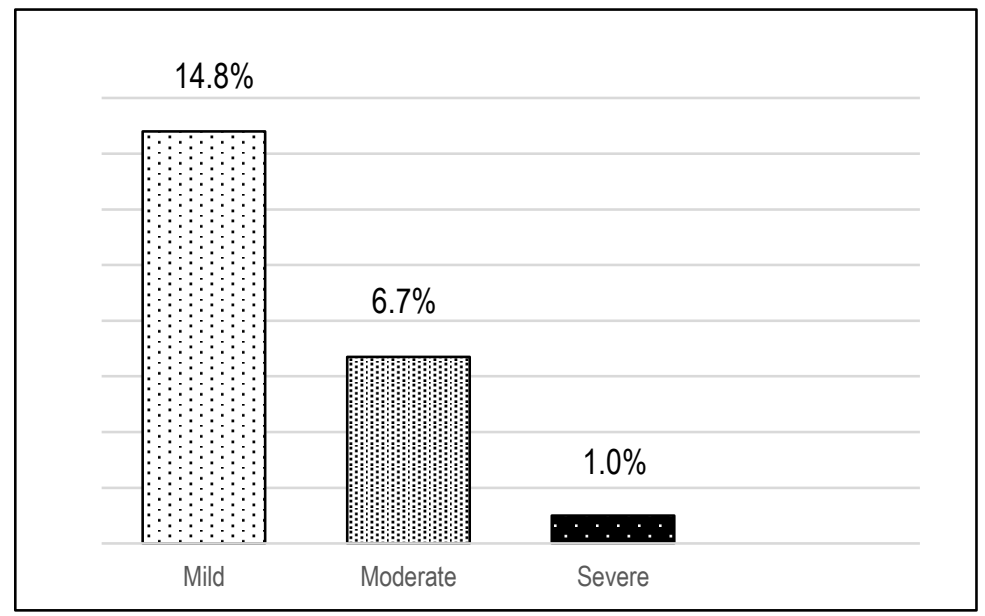

Fig 1: Severity of Depression in Patients with Retroviral Disease 


\subsection{Sociodemographic factors and Major Depressive Disorder}

There was no variable of sociodemographic characteristics that had a statistically significant association with MDD among RVD patients receiving HAART. However, an almost significant result was found for marital status; more than half of the RVD (89\%) were single and less than $50 \%$ of them were living alone. Refer Table 1 for further information.

\subsection{Contributing factors to Major Depressive Disorder}

The significant associations between independent variables and MDD among RVD patients analysed using SLogR include amphetamine-type stimulant (ATS) use for the past three months, history of taking an illicit substance, receiving low to moderate support from family, friends, and significant others, and overall support, CD4 counts ( $\geq 350$ cells/ul), side effects of medications and viral load ( $\geq 20$ copies $/ \mathrm{ml}$ )(Table 2). Multiple logistic regression (MLogR) indicated the four significant predictors for MDD among RVD patients including ATS use for the past three months, receiving low to moderate support from family and significant others, and level of CD4 counts ( $\geq 350$ cells/ul). The use of ATS for the past three months markedly increased the odds of having MDD by 40.23 times (AOR= $40.23 ; p=0.01 ; 95 \% \mathrm{Cl}=3.61-447.86)$. RVD patients who received only low to moderate social support from family and significant others had about 5.65 and 4.36 odds of having RVD ( $A O R=5.65 ; p=0.01 ; 95 \% \mathrm{Cl}=1.43-22.38$ and $\mathrm{AOR}=4.36 ; \mathrm{p}=0.02 ; 95 \% \mathrm{Cl}=1.22-15.64$ ) respectively. Furthermore, having the level of CD4 count of more than 350 cells/ul protected RVD patients from MDD (AOR=0.31; $p=0.03 ; 95 \% \mathrm{Cl}=0.11-0.86)$. The Omnibus test for model coefficient showed that the model was significant $\left(X^{2}(5)=46.08 ; p<0.001\right.$; the Nagelkerke $R^{2}=0.368$; Cox \& Snell $R^{2}=0.197$ ) and the predictive accuracy of the model for the training sample was $85.10 \%$. There was no multicollinearity exist between independent variables; the values for tolerance were more than 0.1 , and VIF was less than 10 for each variable.

Table 1. Background Socio-demography of Patients with RVD and Major Depressive Disorder

\begin{tabular}{|c|c|c|c|c|c|}
\hline \multirow{2}{*}{$\begin{array}{l}\text { Sociodemographic } \\
\text { Factors }\end{array}$} & \multicolumn{5}{|c|}{ Major depressive disorder } \\
\hline & No $(n=183)$ & Yes(n=27) & B & p-value & OR $(95 \% \mathrm{Cl})$ \\
\hline \multicolumn{6}{|l|}{ Age } \\
\hline$<45$ years old & $125(68.3 \%)$ & $21(77.8 \%)$ & 0.49 & 0.32 & $1.62(0.62-4.23)$ \\
\hline$\geq 45$ years old & $58(31.7 \%)$ & $6(22.2 \%)$ & & & \\
\hline \multicolumn{6}{|l|}{ Gender } \\
\hline Male & $160(87.4 \%)$ & $26(96.3 \%)$ & -1.32 & 0.21 & $3.737(0.48-28.88)$ \\
\hline Female & $23(12.6 \%)$ & $1(3.7 \%)$ & & & \\
\hline \multicolumn{6}{|l|}{ Ethnicity } \\
\hline Malay & $98(53.6 \%)$ & $18(66.7 \%)$ & 0.55 & 0.21 & $1.74(0.74-4.06)$ \\
\hline Non-Malay & $85(46.4 \%)$ & $9(33.3 \%)$ & & & \\
\hline \multicolumn{6}{|l|}{ Religion } \\
\hline Islam & $102(55.7 \%)$ & $18(66.7 \%)$ & 0.46 & 0.29 & $1.59(0.68-3.72)$ \\
\hline Others & $81(44.3 \%)$ & $9(33.3 \%)$ & & & \\
\hline \multicolumn{6}{|l|}{ Education } \\
\hline Primary school & $8(4.4 \%)$ & $3(11.1 \%)$ & 1.01 & 0.16 & $2.73(0.68-11.02)$ \\
\hline Secondary to tertiary & $175(95.6 \%)$ & $24(88.9 \%)$ & & & \\
\hline \multicolumn{6}{|l|}{ Employment } \\
\hline Employed & $161(87.0 \%)$ & $22(81.5 \%)$ & -0.51 & 0.35 & $0.60(0.20-1.75)$ \\
\hline Unemployed & $22(12.0 \%)$ & $5(18.5 \%)$ & & & \\
\hline \multicolumn{6}{|l|}{ Total Household income } \\
\hline B40 \& M40 & $154(84.2 \%)$ & $25(92.6 \%)$ & 0.86 & 0.26 & $2.35(0.53-10.49)$ \\
\hline T20 & $29(15.8 \%)$ & $2(7.4 \%)$ & & & \\
\hline \multicolumn{6}{|l|}{ Marital Status } \\
\hline Single/ Widow/Separated/Divorce & $128(69.9 \%)$ & $24(88.9 \%)$ & 1.24 & 0.05 & $3.44(0.99-11.89)$ \\
\hline Married & $55(30.1 \%)$ & $3(11.1 \%)$ & & & \\
\hline \multicolumn{6}{|l|}{ Living companion } \\
\hline With companion & $142(77.6 \%)$ & $19(70.4 \%)$ & -0.38 & 0.41 & $0.69(0.28-1.68)$ \\
\hline Alone & $41(22.4 \%)$ & $8(29.6 \%)$ & & & \\
\hline
\end{tabular}

Table 2. Multiple Logistic Regression of Factors Associated with Major Depressive Disorder

\begin{tabular}{|c|c|c|c|c|c|c|c|c|c|c|}
\hline \multirow[t]{2}{*}{ Variables } & \multicolumn{5}{|c|}{ Simple Logistic Regressions } & \multicolumn{5}{|c|}{ Multiple Logistic Regressions } \\
\hline & $B(d f)$ & p-value & $\mathrm{OR}^{\mathrm{a}}$ & & $\mathrm{Cl}$ & $B(d f)$ & p-value & $A O R^{b}$ & & \\
\hline ATS use for the past three months & $3.13(1)$ & 0.008 & 22.75 & 2.27 & 227.56 & $5.16(1)$ & $0.001^{*}$ & 40.23 & 3.61 & 447.86 \\
\hline LMSS from family & $2.07(1)$ & 0.000 & 7.92 & 2.63 & 23.83 & $1.73(1)$ & $0.01^{*}$ & 5.65 & 1.43 & 22.38 \\
\hline LMSS from significant others & 1.94(1) & 0.000 & 6.94 & 2.51 & 19.16 & $1.47(1)$ & $0.02^{*}$ & 4.36 & 1.22 & 15.64 \\
\hline CD4 counts $\geq 350$ cells/ul & $-1.26(1)$ & 0.003 & 0.28 & 0.12 & 0.65 & $-1.19(1)$ & $0.03^{*}$ & 0.31 & 0.11 & 0.86 \\
\hline Side effects of medications & $1.61(1)$ & 0.002 & 4.99 & 1.76 & 14.12 & $1.10(1)$ & 0.09 & 3.03 & 0.86 & 10.57 \\
\hline LMSS overall & $1.53(1)$ & 0.002 & 4.61 & 1.78 & 11.95 & $0.49(1)$ & 0.59 & 1.63 & 0.27 & 9.91 \\
\hline Viral load $\geq 20$ copies $/ \mathrm{ml}$ & 1.42(1) & 0.001 & 4.15 & 1.74 & 9.94 & 1.10(1) & 0.59 & 3.01 & 0.96 & 9.49 \\
\hline History of taking illicit substance & $0.89(1)$ & 0.04 & 2.45 & 1.01 & 5.96 & $0.34(1)$ & 0.63 & 1.36 & 0.39 & 4.62 \\
\hline LMSS from friends & $1.02(1)$ & 0.03 & 2.78 & 1.07 & 7.21 & $0.32(1)$ & 0.70 & 1.38 & 0.26 & 7.19 \\
\hline
\end{tabular}

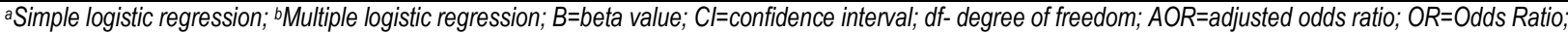
*significant $p$ value $<0.05$; ** significant $p$ value $<0.01$; ATS=Amphetamine-type stimulant; LMSS=Low and moderate social support 


\subsection{Discussion}

The main contributing factors of MDD are the use of ATS for the past three months, the low and moderate social support from family and significant others as well as a CD4 count less than 350 cells/ul. ATS drugs include amphetamine, methamphetamine and ecstasy or 3,4-methylenedioxyethylamphetamine (MDMA) (Massaro et al., 2017). The ATS recent use increases about 40-fold of chances for RVD patients to get MDD. Researchers indicated that ATS directly damages the brain, suppresses the immune system and increases cytokine levels of RVD patients (Schuster \& Gonzalez, 2012). Its neurotoxicity increases the risk of depression among the RVD patients (Zeng et al., 2018). Furthermore, abstinent from ATS among those who had already dependent on this drug can manifest with symptoms of MDD, including a dysphoric state and low motivation (Amiri et al., 2016). In view of that, the awareness of the consequences of taking illicit substances must be emphasised continuously as well as the encouragement of living a healthy lifestyle without drugs.

Our study indicated the importance of the support system in particular, support from family and other significant people in the life of RVD patients. The complimentary messages and perceptions from the family could reduce the rumination of hopelessness and improve self-esteem in continuing the treatment among patients with chronic illness (Pernice-Duca, 2010). The patients with RVD face multiple challenges in their life, including career, relationship with family and others. An individual needs support from family as a source of security, acceptance and worthiness; hence this group of patients feel fear of rejection and being labelled by the family members (Tuan Abdullah et al., 2019). Therefore, lack of rejection and adequate support from the family could lessen the pessimism and encourage RVD patients to cope well with the stress as well as reduce the risk of having psychological disorder which leads to proper treatment adherence (Dejman et al., 2015). Higher perceived social support from family, especially emotional or informational, reduce the risk of having depression among RVD patients (Matsumoto et al., 2017). The significant others are one's closest and most trusted individual that could be mothers, fathers, relatives and friends (Cheng \& Starks, 2002). RVD is a manageable chronic disease exposed to numerous psychosocial challenges. Thus, RVD patients need countless support from others, especially the close one. It starts from the first moment when they received the bad news informing that they are infected by HIV.

CD4 is a type of white blood cells, named T-cells which is also known as regulatory T cells which acts by reducing the excessive immune response and regulate immune tolerance (Workman, Szymczak-Workman, Collison, Pillai, \& Vignali, 2009). CD4 stimulates the production of anti-inflammatory cytokines such as interleukin-10 and subsequently regulate inflammatory responses (Miyara et al., 2009). Our study indicated that the level of CD4 is a crucial determinant for MDD among RVD patients. Those who have CD4 counts more than 350 cells/ul are protected from having MDD. This result supported the findings of other researchers elsewhere (Terloyeva et al., 2018). HIV may infect and kill CD4 cells which cause the failure of the immune system (Aavani \& Allen, 2019). Therefore, CD4 cells play a critical role to inhibit the worsening of the inflammatory process before developing depression that occurs during stressful experiences. On the other hand, when the immune system is low due to reduced CD4 counts, it may lead to abnormality in the cascade of neurohormonal changes at the Hypothalamus-Pituitary-Adrenal Gland (HPA) resulted in depletion of the precursor of serotonin which can lead to depression (Masih \& J.M.I. Verbeke, 2018). The level of CD4 count is negatively correlated with MDD among RVD patients, therefore, it is recommended that the physicians to strengthen the education on adherence of HAART to achieve the optimal CD4 counts more than 350 cells/ul and to ensure optimum immunity in reducing the risk of getting depression.

\subsection{Conclusion and Recommendations}

This study indicated that the use of ATS for the past three months, receiving only low to moderate social support from family and significant others as well as having CD4 count less than 350 cells/ul increase the risk of RVD patients for MDD. The findings may inform clinicians on the needs for early intervention, including counselling for RVD patients who are abusing drugs and increasing support system for them. Addressing these psychological aspects is essential so that the detrimental effects of MDD such as premature dementia, psychosis and suicide can be prevented early. Minimising the psychological consequences of this chronic and stigmatising illness can help them to have optimum quality of life. Moreover, enhancing their adherence to the HAART may improve the CD4 counts to $\geq 350$ cells/ul, which could lessen the odds of getting MDD. This study provides insights to the contributing factors of MDD among the RVD patients; nevertheless, we would like to inform that the study was limited by its design and suggest a more robust prospective study, and larger sample sizes to determine the causal factors for MDD among the RVD patients. We are aware that many other physical, personal and environmental factors that could influence MDD among them.

\section{Acknowledgement}

We would like to thank the Director-General of Health Malaysia for his permission to publish this article and to express our appreciation to all the study participants who had volunteered to participate in this study. We would like to express our gratitude to the senior lecturer and consultant of public health medicine, Dr Ikhsan Selamat, and Dr Semran Kaur, a psychiatrist in Hospital Sungai Buloh who were directly involved in this study. The authors received no financial support for the research, authorship or publication of this article and declared no conflict of interest.

\section{References}

Aavani, P., \& Allen, L. J. (2019). The role of CD4 T cells in immune system activation and viral reproduction in a simple model for HIV infection. Applied Mathematical Modelling, 75, 210-222. 
Amiri, S., Alijanpour, S., Tirgar, F., Haj-Mirzaian, A., Amini-Khoei, H., Rahimi-Balaei, M., . . Zarrindast, M.-R. (2016). NMDA receptors are involved in the antidepressantlike effects of capsaicin following amphetamine withdrawal in male mice. Neuroscience, 329, 122-133.

Cheng, S., \& Starks, B. (2002). Significant Others on students' educational expectations. Sociology of Education, 75(4), 306-327.

Dejman, M., Ardakani, H. M., Malekafzali, B., Moradi, G., Gouya, M. M., Shushtari, Z. J., . . Mohraz, M. (2015). Psychological, social, and familial problems of people living with HIVIAIDS in Iran: A qualitative study. Int J Prev Med, 6.

Deshmukh, N. N., Borkar, A. M., \& Deshmukh, J. S. (2017). Depression and its associated factors among people living with HIVIAIDS: Can it affect their quality of life? J Family Med Prim Care, 6(3), 549-553. doi:10.4103/2249-4863.222016

Fawzi, M. C. S., Eustache, E., Oswald, C., Louis, E., Surkan, P. J., Scanlan, F., ... Mukherjee, J. S. (2012). Psychosocial support intervention for HIV-affected families in Haiti: implications for programs and policies for orphans and vulnerable children. Social science \& medicine, 74(10), 1494-1503.

Hostinar, C. E., \& Gunnar, M. R. (2015). Social Support Can Buffer against Stress and Shape Brain Activity. AJOB Neurosci, 6(3), $34-42$. doi:10.1080/21507740.2015.1047054

Masih, J., \& J.M.I. Verbeke, W. (2018). Immune System Function and its Relation to Depression: How Exercise can Alter the Immune System-Depression Dynamics. Journal of Depression and Anxiety, 07(04). doi:10.4172/2167-1044.1000325

Massaro, Abdalla, Laranjeira, Caetano, Pinsky, \& Madruga. (2017). Amphetamine-type stimulant use and conditional paths of consumption: data from the Second Brazilian National Alcohol and Drugs Survey. Braz J Psychiatry, 39(3), 201-207. doi:10.1590/1516-4446-2015-1894

Matsumoto, S., Yamaoka, K., Takahashi, K., Tanuma, J., Mizushima, D., Do, C. D., .. Oka, S. (2017). Social Support as a Key Protective Factor against Depression in HIV-Infected Patients: Report from large HIV clinics in Hanoi, Vietnam. Sci Rep, 7(1), 15489. doi:10.1038/s41598-017-15768-w

Mimiaga, M. J., Reisner, S. L., Grasso, C., Crane, H. M., Safren, S. A., Kitahata, M. M., . . Mayer, K. H. (2013). Substance use among HIV-infected patients engaged in primary care in the United States: Findings from the centers for AIDS Research Network of Integrated Clinical Systems Cohort. American Journal of Public Health, 103(8), 1457-1467. doi:10.2105/AJPH.2012.301162

Miyara, M., Yoshioka, Y., Kitoh, A., Shima, T., Wing, K., Niwa, A., .. Valeyre, D. (2009). Functional delineation and differentiation dynamics of human CD4+ T cells expressing the FoxP3 transcription factor. Immunity, 30(6), 899-911.

Mukhtar, F., Bakar, A. K. A., Junus, M. M., Awaludin, A., Azizt, S. A., Midin, M., .. Kaur, J. (2012). A preliminary study on the specificity and sensitivity values and interrater reliability of mini international neuropsychiatric interview (MINI) in Malaysia. ASEAN Journal of Psychiatry, 13(2).

Ngum, A., Fon, P. N., Ngu, R. C., Verla, V. S., \& Luma, H. N. (2017). Depression Among HIV/AIDS Patients on Highly Active Antiretroviral Therapy in the Southwest Regional Hospitals of Cameroon: A Cross-Sectional Study. Neurology and Therapy, 6(1), 103-114. doi:10.1007/s40120-017-0065-9

Østergaard, S. D., Foldager, L., Allgulander, C., Dahl, A. A., Huuhtanen, M.-T., Rasmussen, I., \& Munk-Jørgensen, P. (2010). Psychiatric caseness is a marker of major depressive episode in general practice. Scandinavian journal of primary health care, 28(4), 211-215.

Pernice-Duca, F. (2010). Family network support and mental health recovery. Journal of Marital and Family Therapy, 36(1), 13-27.

Radzniwan, R., Alyani, M., Aida, J., Khairani, O., Nik Jaafar, N. R., \& Tohid, H. (2016). Psychological status and its clinical determinants among people living with HIV/AIDS (PLWHA) in Northern Peninsular Malaysia. HIV \& AIDS Review, 15(4), 141-146. doi:10.1016/j.hivar.2016.11.002

Shane, Koh, \& Cheah. (2010). Psychiatric morbidity among HIV patients in Hospital Tuanku Jaafar, Seremban, Malaysia. HIVIAIDS Prevention, Treatment and Care: The Way Forward. Universiti Sains Malaysia, Penang, AIDS Action \& Research Group., 85-101.

Schuster, R. M., \& Gonzalez, R. (2012). Substance abuse, hepatitis C, and aging in HIV: common cofactors that contribute to neurobehavioral disturbances. Neurobehavioral HIV Medicine, 2012(4), 15. doi:10.2147/NBHIV.S17408

Seffren, V., Familiar, I., Murray, S. M., Augustinavicius, J., Boivin, M. J., Nakasujja, N., . . Bass, J. (2018). Association between coping strategies, social support, and depression and anxiety symptoms among rural Ugandan women living with HIVIAIDS. AIDS Care, 30(7), 888-895. doi:10.1080/09540121.2018.1441969

Terence, Sidi, Choy, \& Mahadevan. (2017). Prevalence of Depressive Disorder and Its Association With Perceived Social Support Among Patients With Human Immunodeficiency Virus (Hiv) in Hospital Tuanku Jaafar, Seremban (Htjs), Malaysia. ASEAN Journal of Psychiatry, 18(1), 10-19.

Terloyeva, D., Nugmanova, Z., Akhmetova, G., Akanov, A., Patel, N., Lazariu, V., ... McNutt, L. A. (2018). Untreated depression among persons living with human immunodeficiency virus in Kazakhstan: A cross-sectional study. PLOS ONE, 13(3), e0193976. doi:10.1371/journal.pone.0193976

Tesfaye, S. H., \& Bune, G. T. (2014). Generalised psychological distress among HIV-infected patients enrolled in antiretroviral treatment in Dilla University Hospital, Gedeo zone, Ethiopia. 1, 1-9.

Todd, J. V., Cole, S. R., Pence, B. W., Lesko, C. R., Bacchetti, P., Cohen, M. H., ... Mack, W. (2017). Effects of antiretroviral therapy and depressive symptoms on allcause mortality among HIV-infected women. American journal of epidemiology, 185(10), 869-878.

Tran, B. X., Ho, R. C. M., Ho, C. S. H., Latkin, C. A., Phan, H. T., Ha, G. H., .. Zhang, M. W. B. (2019). Depression among Patients with HIV/AIDS: Research Development and Effective Interventions (GAPRESEARCH). Int J Environ Res Public Health, 16(10). doi:10.3390/ijerph16101772

Tuan Abdullah, Mat Min, Hossain, \& Abdullah. (2019). Relationship and career challenges faced by people infected with HIV in Malaysia. F1000Research, 8. doi:10.12688/f1000research.21079.1 
Tull, M. T., Berghoff, C. R., Bardeen, J. R., Schoenleber, M., \& Konkle-Parker, D. J. (2018). An initial open trial of a brief behavioral activation treatment for depression and medication adherence in HIV-infected patients. Behavior modification, 42(2), 196-209.

Tyree, G. A., Vaida, F., Zisook, S., Mathews, W. C., \& Grelotti, D. J. (2019). Clinical correlates of depression chronicity among people living with HIV: What is the role of suicidal ideation? Journal of affective disorders, 258, 163-171.

Workman, C. J., Szymczak-Workman, A. L., Collison, L. W., Pillai, M. R., \& Vignali, D. A. (2009). The development and function of regulatory T cells. Cellular and Molecular Life Sciences, 66(16), 2603.

Word Health Organization (WHO). (2019). HIVIAIDS. Retrieved from https://www.who.int/news-room/fact-sheets/detail/hiv-aids

Yahya, F., \& Othman, Z. (2015). Validation of the Malay version of the hospital anxiety and depression scale (HADS) in Hospital Universiti Sains Malaysia. Int Med J, 22(2), 80-82.

Yee, Gee, Guan, Teong, \& Kamarulzaman. (2009). Identifying depression among the human immunodeficiency virus (HIV) patients in University Malaya Medical Centre Kuala Lumpur, Malaysia. Asian J Psychiatry, 10(2), 1-13.

Zeng, C., Guo, Y., Hong, Y. A., Gentz, S., Zhang, J., Zhang, H., . . Cai, W. (2019). Differential effects of unemployment on depression in people living with HIVIAIDS: a quantile regression approach. AIDS Care, 1-8. doi:10.1080/09540121.2019.1587366

Zeng, X.F., LI, Q., LI, J., Wong, N., LI, Z., Huang, J., .. . Lu, G. (2018). page: HIV-1 Tat and methamphetamine co-induced oxidative cellular injury is mitigated by Nacetylcysteine amide (NACA) through rectifying mTOR signaling. 